\title{
Flight Test of $\mathrm{L}_{1}$ Adaptive Control Law:
}

\section{Offset Landings and Large Flight Envelope Modeling Work}

\author{
Irene M. Gregory ${ }^{1}$ \\ NASA Langley Research Center, Hampton, VA 23681-2199, USA \\ Enric Xargay ${ }^{2}$ \\ University of Illinois at Urbana-Champaign, Urbana, Illinois 61801 \\ Chengyu $\mathrm{Cao}^{3}$ \\ University of Connecticut, Storrs, CT 06269 \\ Naira Hovakimyan ${ }^{4}$ \\ University of Illinois at Urbana-Champaign, Urbana, Illinois 61801
}

\begin{abstract}
This paper presents new results of a flight test of the $L_{1}$ adaptive control architecture designed to directly compensate for significant uncertain cross-coupling in nonlinear systems. The flight test was conducted on the subscale turbine powered Generic Transport Model that is an integral part of the Airborne Subscale Transport Aircraft Research system at the NASA Langley Research Center. The results presented include control law evaluation for piloted offset landing tasks as well as results in support of nonlinear aerodynamic modeling and real-time dynamic modeling of the departure-prone edges of the flight envelope.
\end{abstract}

\section{Introduction}

$\mathrm{O}$ ne of the primary objectives of the Integrated Resilient Aircraft Control (IRAC) Project, under the auspices of the Aviation Safety Program, was to advance the state of the art in adaptive control technology. Of particular interest is piloted flight under adverse conditions such as unusual attitudes, surface failures and structural damage. The IRAC Project and its successor, Vehicle Safety Systems Technologies, is using subscale flight testing as an important tool in the evaluation of experimental control laws. This is particularly beneficial for the test and evaluation of control law performance beyond the edge of the normal flight envelope, where the risk of vehicle loss is high due to limited knowledge of nonlinear aerodynamics beyond stall and the potential for high structural loads. The Airborne Subscale Transport Aircraft Research (AirSTAR) ${ }^{1-3}$ system at the NASA Langley Research Center has been designed to provide a flexible research environment with the ability to conduct rapid prototyping and testing for control algorithms in extremely adverse flight conditions. Further background on the problem and results from previous flight tests of an $\mathrm{L}_{1}$ adaptive control law can be found in Ref. 4.

\footnotetext{
${ }^{1}$ Senior Research Engineer, NASA Langley Research Center, Hampton, VA 23681-2199, AIAA Associate Fellow

${ }^{2}$ Graduate Student, Department of Aerospace Engineering, AIAA Student Member

${ }^{3}$ Assistant Professor, Department of Mechanical Engineering, AIAA Member

${ }^{4}$ Professor, Department of Mechanical Science and Engineering, AIAA Associate Fellow
}

1 of 15

American Institute of Aeronautics and Astronautics 
This paper presents new results from flight tests of an $\mathrm{L}_{1}$ adaptive control law conducted in September 2010 and May 2011 at Ft. Pickett, VA. During the September 2010 deployment, the objectives for an $\mathrm{L}_{1}$ control law were two fold. The first objective was continuation of control law stability and performance evaluation during offset landing task at various levels of aircraft stability. The second objective was to support large envelope modeling work that included nonlinear unsteady aerodynamics at post-stall high angles of attack, and instrumentation calibration for angle of attack and sideslip angle. The results of the calibration work and the precision tracking of large values of angle of attack and sideslip can be found in Ref. 6. During the May 2011 deployment, the objectives for an $\mathrm{L}_{1}$ adaptive control law were to continue nonlinear unsteady aerodynamic modeling around the stall regime and to facilitate real-time model identification at various flight conditions including departure-prone parts of the flight envelope where the aircraft is no longer fully controllable. The flight tasks, changes to the aircraft dynamics and relevant flight conditions are described in detail in the paper.

The paper is organized as follows. Section II provides a brief AirSTAR flight test facility overview with emphasis on flight control law implementation environment. Brief summary of an $\mathrm{L}_{1}$ adaptive control law, $\alpha$, $\mathrm{p}-\beta$ CAS, is presented in Section III. Section IV describes the flight test results. Section V presents concluding remarks and describes future research plans.

\section{AirSTAR Overview}

AirSTAR is an integrated flight test infrastructure which utilizes remotely piloted, jet powered subscale models for flight testing. One particular use of AirSTAR is flight testing research control laws in adverse flight conditions. AirSTAR consists of a remotely piloted subscale test article, the Mobile Operations Station (MOS) (an integrated ground station and control room), and a test range. Description of AirSTAR Concept of Operations can be found in Ref. 1-3. The research pilot executes a flight test plan from a research cockpit located in the MOS, which utilizes synthetic vision displays driven with aircraft sensor data. The research pilot uses a ground-based flight control system (FCS) that is connected to the aircraft through a telemetry link and is illustrated in Fig. 1.

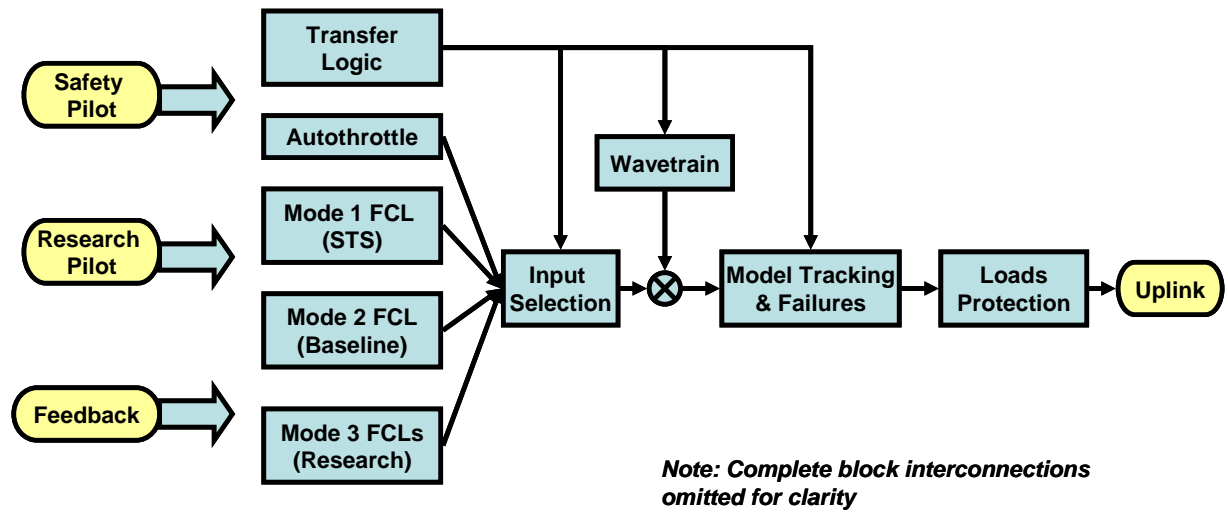

Figure 1. AirSTAR FCS Flight Control Laws Architecture

Currently, AirSTAR's primary test aircraft is a 5.5\% dynamically scaled twin-turbine powered generic transport model (GTM) shown in Fig 2. Dynamic scaling (i.e., similitude using equal Froude number and relative density between model-scale and full-scale) allows subscale flight test results to be applied to full-scale aircraft. This model (tail number T2) has a $6.5 \mathrm{ft}$ wingspan, weighs $54 \mathrm{lbs}$ at takeoff, and has a flight time of approximately 15 minutes. The aircraft is outfitted with full flight test instrumentation, including angle of attack and angle of sideslip vanes, sensors measuring static and dynamic pressure, control surface positions, rate gyros and accelerometers, a 6-DOF INS/GPS package, and engine instrumentation. Downlink data update rates vary from $5 \mathrm{~Hz}$ on the GPS data to $200 \mathrm{~Hz}$ on the data from analog sensors. Uplink commands are transmitted at $200 \mathrm{~Hz}$.

\section{2 of 15}

American Institute of Aeronautics and Astronautics 

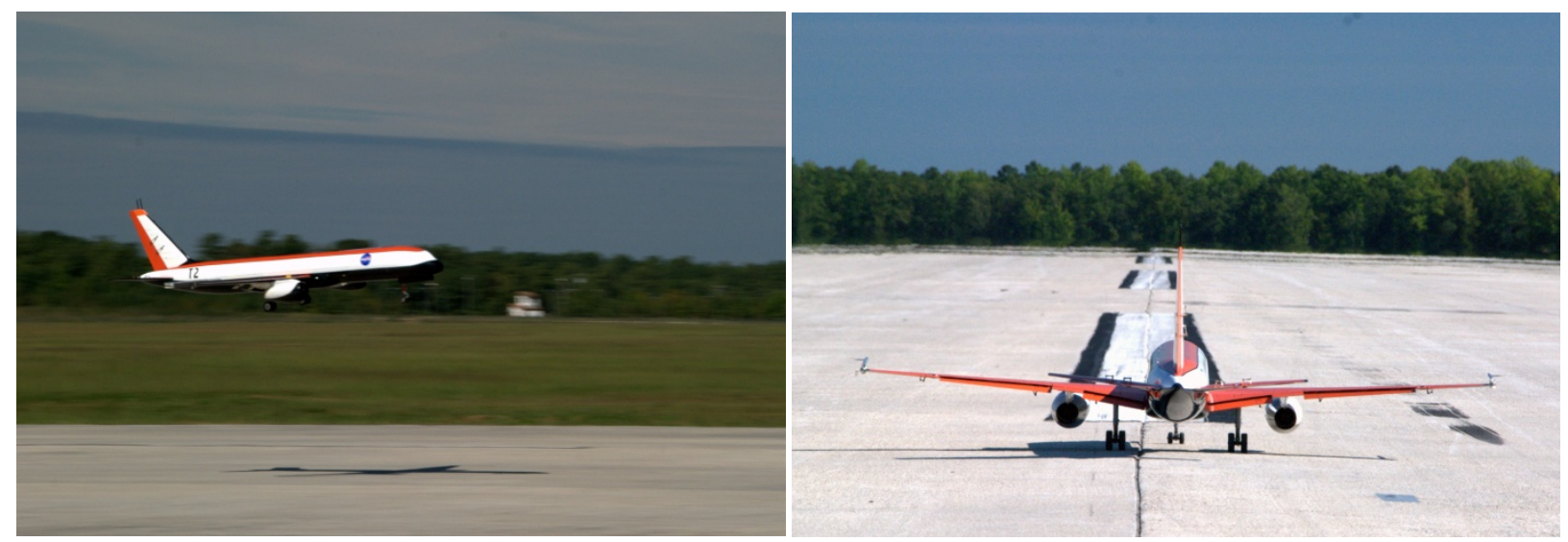

Figure 2. AirSTAR Test Aircraft

It is important to note that the T2 aircraft has split surfaces - 4 elevator segments, inboard/outboard, left/right; right/left aileron; 2 rudder segments, upper/lower; flaps and spoilers. Segmented surfaces allow emulation of a range of failures that go beyond surface failures and include aerodynamic stability variations. The research flight control law (FCL) resides in the Flight Control System/Research Control Law Module, referred to as Mode 3 in Fig. 1, which is executed on a different processor and can contain any number of control laws, though only one can be operational at any one time. Furthermore, the current operational research flight envelope for the T2 Model, enforced by the loads protection system, is $600 \leq$ Alt $\leq 1500 \mathrm{ft}, 40 \leq V \leq 100$ knots equivalent airspeed and $3.5 \mathrm{~g}$ load limit.

\section{L1 adaptive control laws for the GTM}

The research control law developed for the GTM aircraft has as its primary objective achieving tracking for a variety of tasks with guaranteed stability and robustness in the presence of uncertain dynamics, such as changes due to rapidly varying flight conditions during standard maneuvers, and unexpected failures. Ideally, all of this must be achieved while providing Level 1 handling qualities under nominal as well as adverse flight conditions. The $\mathrm{L}_{1}$ control system presented in Fig. 3 is a three axes angle of attack $(\alpha)$, roll rate (p) - sideslip angle ( $\beta$ ) command augmentation system. The $\alpha$-command was chosen for reasons described below and the p- $\beta$ command is one of the standard lateral-directional response types. The details on the control law design and the underlying theory can be found in Ref. 4 and 5.

The desired control system behavior is to provide a decoupled response between longitudinal and lateraldirectional axes, as well as, between lateral and directional axes as much as possible. The longitudinal $\alpha$-command response type was chosen for two reasons. One, the operational baseline control law is $\alpha$-command so the same response would make direct control law comparison relevant. And more importantly, other research tasks performed on the GTM require precise $\alpha$ control. However, $\alpha$-command control law brings its own challenges to adaptive control formulation. In a typical aircraft, without direct lift devices, control acts through moment generating effectors, which implies that the uncertainty propagates through moment equations of motion and any uncertainty in $\alpha$ would generate significant cross-coupling effects. This cross-coupling uncertainty, also referred to as unmatched uncertainty, is uncertainty that does not enter through the range of the control effectiveness matrix B. In addition, the phugoid mode of a dynamically scaled aircraft is much closer in frequency to the short period dynamics. The combination of $\alpha$-command response type and faster phugoid dynamics result in a significant level of unmatched uncertainties. In fact, it is the desire for an $\alpha$-command that motivated the development of an $\mathrm{L}_{1}$ adaptive control architecture that compensates for the cross-coupling uncertainties. Furthermore, for inner-loop FCS design, the effects of slow outer-loop variables (e.g. airspeed, pitch angle, bank angle) may appear as unmatched uncertainties in the dynamics of the fast inner-loop variables that are being regulated (e.g. angle of attack, sideslip angle, roll 
rate). Also, unmodeled nonlinearities, cross-coupling between channels, and dynamic asymmetries may introduce unmatched uncertainties in the inner-loop system dynamics. If the design of the inner-loop FCS does not account for these uncertainties, their effect on the inner-loop dynamics will require continuous compensation by the pilot, thereby increasing the pilot's workload. Therefore, automatic compensation for the undesirable effects of these unmatched uncertainties on the output of the system is critical to achieve desired performance, reduce pilot workload, and improve the aircraft's handling qualities.

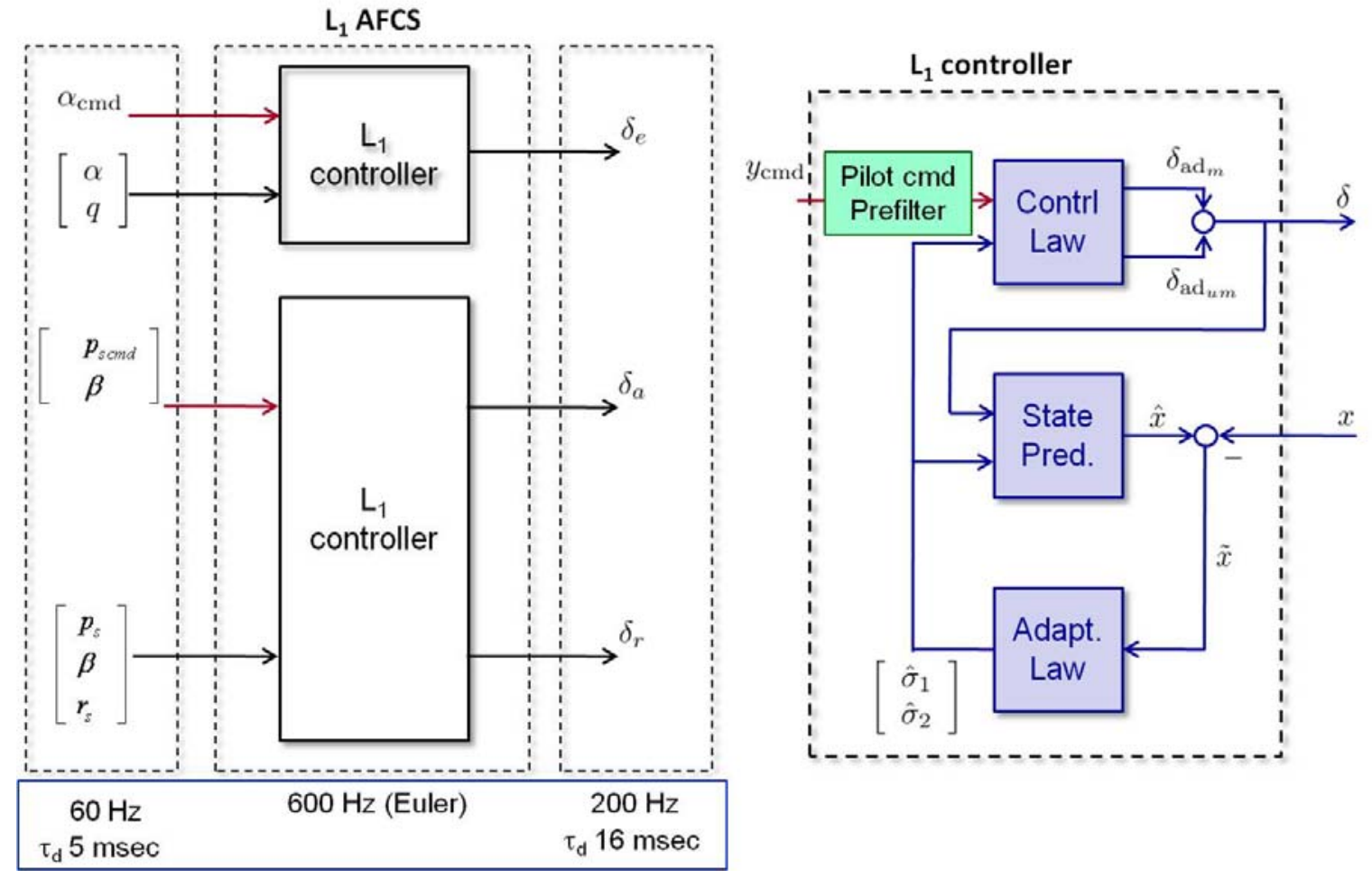

Figure 3. $\mathrm{L}_{1}$ all-adaptive controller architecture.

The control law architecture is outlined in Fig. 3. The design of the control laws incorporated the best practices from classical flight control law design by using the pilot command shaping filters to properly decouple vehicle response along the longitudinal, lateral and directional axes. Moreover, the desired system dynamics for the GTM are given by

$$
\begin{aligned}
\dot{x}_{m} & =A_{m} x_{m}+B_{m} \delta_{c m d} \\
\left(\begin{array}{c}
\dot{\alpha} \\
\dot{q}
\end{array}\right) & =\left(\begin{array}{cc}
\frac{Z_{\alpha}}{V} & 1+\frac{Z_{q}}{V} \\
M_{\alpha} & M_{q}
\end{array}\right)\left(\begin{array}{c}
\alpha \\
q
\end{array}\right)+\left(\begin{array}{c}
\frac{Z_{\delta}}{V} \\
M_{\delta_{e}}
\end{array}\right) \delta_{e}
\end{aligned}
$$

in the longitudinal axis for $\alpha$-command and

$$
\left(\begin{array}{c}
\dot{p} \\
\dot{\beta} \\
\dot{r}
\end{array}\right)=\left(\begin{array}{ccc}
L_{p} & 0 & 0 \\
0 & Y_{\beta} / V & -1 \\
0 & N_{\beta} & N_{r}
\end{array}\right)\left(\begin{array}{l}
p \\
\beta \\
r
\end{array}\right)+\left(\begin{array}{cc}
L_{\delta a} & L_{\delta r} \\
Y_{\delta a} & Y_{\delta r} \\
N_{\delta a} & N_{\delta r}
\end{array}\right)\left(\begin{array}{l}
\delta_{a} \\
\delta_{r}
\end{array}\right)
$$

for the lateral-directional axes p- $\beta$ command. Matrices $A_{m}$ and $B_{m}$ are chosen such that $A_{m}$ is Hurwitz and Level 1 handling qualities requirements ${ }^{7}$ are satisfied. 
An $\mathrm{L}_{1}$ adaptive control law was designed for a nominal system at $V=80$ KEAS and Alt $=1000 \mathrm{ft}$ which corresponds to $\alpha \approx 4.5 \mathrm{deg}$. The nominal GTM model has $21 \mathrm{msec}$ latency due to processing (16 msec on surface commands and 5 msec on sensor outputs). As indicated in Fig. 3 the telemetry uplink and downlink are updated at $200 \mathrm{~Hz}$ and the control law itself runs at $600 \mathrm{~Hz}$ on a flight computer. One further item of note, an $\mathrm{L}_{1}$ adaptive controller was designed strictly for pilot in the loop flying, hence the tuning was done for piloted flight and there is no outer loop compensation to hold altitude or pitch attitude.

Based on the performance during the June 2010 flight test, an $\mathrm{L}_{1}$ adaptive control law was tasked with supporting the modeling work in the post-stall environment that required highly precise tracking of angle of attack at stall and post-stall flight conditions. Changes made to an $\mathrm{L}_{1}$ adaptive controller to improve AOA tracking performance in post-stall regime for September 2010 and subsequent deployments were:

1. The lateral/directional control law feedback was changed from body to stability axis for roll and yaw, rates.

2. A stability augmentation (SAS) feedback was added in roll rate for $11<\alpha<17$ to improve roll response damping.

3. The bandwidth of AoA low pass filter was increased to improve precision tracking around and just poststall. The penalty for this improved performance was decreased tolerance to time delay (from $146 \mathrm{msec}$ to 116 msec total latency) which is consistent with and is predicted by theory.

The results for a variety of test cases are presented in the next section.

\section{Flight test results}

The material presented in this section are the results of a flight test of an $\mathrm{L}_{1}$ adaptive controller flown on a twin turbine-powered, dynamically scaled GTM AirSTAR aircraft (tail number T2) conducted in September 2010 and May 2011 at Ft. Pickett, VA. As mentioned previously the $\mathrm{L}_{1}$ adaptive $\alpha$, $\mathrm{p}-\beta$ command response control laws were designed for a nominal aircraft at a single flight condition ( $V=80$ KEAS). The flight test was conducted in strict adherence to the procedures outlined in the flight test $\operatorname{plan}^{9,11}$ and the test cards ${ }^{8,10}$, relevant sections of which are reproduced here to provide the necessary background to put the presented results in the appropriate context. The last set of tasks in the stability and control evaluation series were offset landing tasks described below.

\section{A. Objective 1 - Offset landing, simultaneous static stability and roll damping degradation}

In order to conduct a handling qualities evaluation of the research control laws a simulated offset landing was developed as a high workload task. Offset landing is considered a very challenging maneuver due to proximity to the ground, requirement for high level of precision and associated high workload. Executing the maneuver typically involves a series of S-turns as the pilot attempts to realign the aircraft with the center of the runway during the final part of the approach to land. This task is a demanding lateral task that would expose any potential issues with a control law. In addition to performing the task with nominal dynamics, the stability of the aircraft was degraded to fly a neutrally stable case, $\Delta \mathrm{Cm} \alpha / \mathrm{Clp}=100 \%$, and a highly unstable case, $\Delta \mathrm{Cm} \alpha / \mathrm{Clp}=125 \%$. The notation $\Delta \mathrm{Cm} \alpha / \mathrm{Clp}$ is a short hand to indicate that there is a simultaneous change in $\mathrm{Cm}_{\alpha}$ and in $\mathrm{Cl}_{\mathrm{p}}$ stability derivatives; hence in words, it read e.g. " $100 \%$ change in $\mathrm{Cm}_{\alpha}$ and in $\mathrm{Cl}_{\mathrm{p}}$ simultaneously". The particulars of the maneuver executed during flight test are as follows:

- Initial offset at the maneuver initiation:

- $90 \mathrm{ft}$. lateral, $1800 \mathrm{ft}$. downrange, $100 \mathrm{ft}$. above the runway

- Performance boundaries at touchdown:

- Desired $-|\phi|= \pm 10$ deg; $|\gamma|= \pm 1$ deg; landing box = 24’ $x 328$ '

- Adequate - $|\phi|= \pm 20 \mathrm{deg} ;|\gamma|= \pm 3$ deg; landing box = 9’x30'

- Handling qualities ratings taken for nominal, neutrally stable and unstable airplane

The pilot was concentrating primarily on the landing boxes with some attention being paid to the bank angle performance; minimal attention was paid to the flight path angle due to high workload of the task.

\section{5 of 15}

American Institute of Aeronautics and Astronautics 
The pilot sees offset from the runway centerline in the Heads Up Display (HUD), illustrated in Fig. 4, and then attempts to land in the desired box on the runway within specified performance boundaries on aircraft attitude. In addition to the desired and adequate landing boxes, the HUD provides desired bank angle and flight path indicators to assist in the task. As soon as the aircraft touches the simulated runway, the test engineer releases the offset button and the actual aircraft position reappears on the HUD. The research pilot then completes the Cooper-Harper rating (CHR) ${ }^{12}$ evaluation chart to provide handling qualities rating. Note that CHR ratings are task specific and relate aircraft performance to amount of effort required from the pilot to achieve the level of performance. The chart is divided into major performance categories such as achieved desired performance, Level 1, adequate performance, Level 2, not achieved adequate performance, Level 3. Each one of these levels is further divided into 3 sections that provide gradations to the level of effort ranging from 'pilot compensation not a factor", CHR1, to "intense pilot compensation is required to maintain control”, CHR9. CHR 10 is a standalone rating that marks loss of control at least during some part of the task being performed.

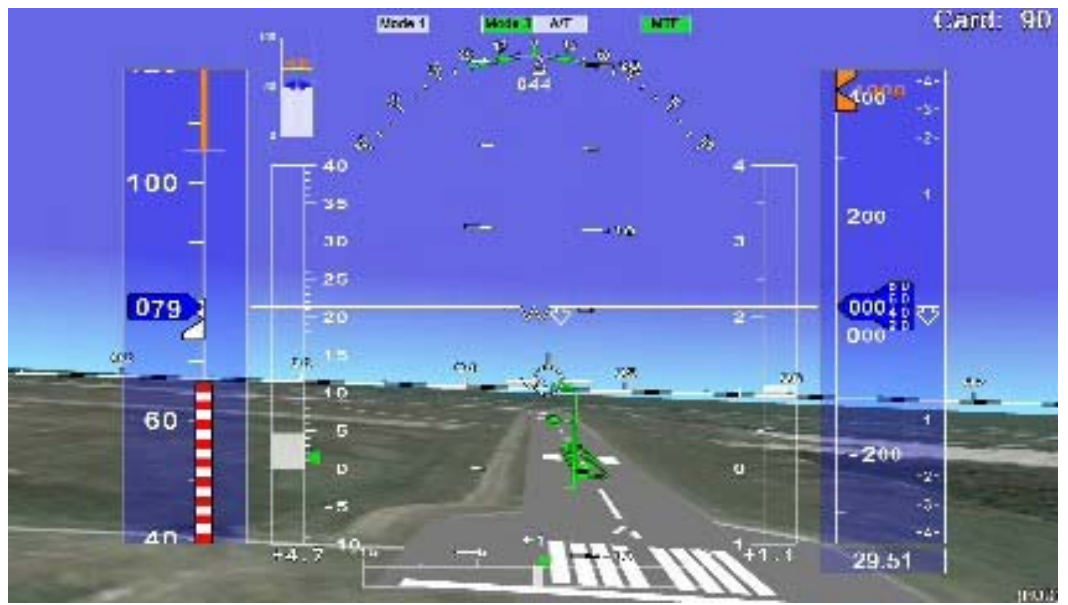

Figure 4. Offset landing as seen on the research pilot Heads Up Display.

During a research flight, the pilot performs one practice offset landing with nominal aircraft dynamics, followed by an offset landing for CHR rating. Moreover, in order to evaluate the ability of the adaptive controller, the task is performed, not only for the nominal aircraft, but also for the cases of neutrally stable aircraft, $\Delta \mathrm{Cm} \alpha / \mathrm{Clp}=100 \%$, and highly unstable aircraft, $\Delta \mathrm{Cm} \alpha / \mathrm{Clp}=125 \%$, each with an additional $50 \%$ reduction in pitch control authority (2 interior elevator segments are used to destabilize $\mathrm{Cm} \alpha$ ) .

One important item to note regarding stability degradation is the influence of turbulence. Due to the nature of the stability degradation implementation, scheduling of surfaces with the sensor based AOA and roll rate, turbulence tends to increase the surface deflections thus further destabilizing the aircraft. Technical analysis had not been performed to date to precisely correlate the level of turbulence to the exact change in Cmo and Clp. During offset landing tasks flights light turbulence was present and the stability degradation induced by the control surfaces was to some degree greater than assessments performed in simulation with no turbulence, thus, the neutrally stable aircraft was slightly unstable and the unstable case was even more so.

To put the flight test results in the appropriate context note that the GTM, with Mode 1 FCS (stick-to-surface), is rated CHR 3, Level 1 handling qualities in general; this rating deteriorates to CHR 4, Level 2 handling qualities, for the offset landing task of a nominal aircraft. Moreover, for the neutral stability case, $100 \%$ roll- and pitch-axis stability degradation, the pilot rated the task as CHR 10, aircraft uncontrollable with catastrophic landing expected.

Under nominal aircraft stability, the $\mathrm{L}_{1}$ control law is rated CHR 3, Level 1 handling qualities. For the case of $100 \%$ stability degradation, the $\mathrm{L}_{1}$ controller experiences some handling qualities degradation and is rated CHR 5 , Level 2. Finally, for the case of 125\% stability degradation, the pilot achieves a safe landing with CHR 7, Level 3 handling qualities. It is important to note that among all of the controllers tested for the IRAC Project, the $\mathrm{L}_{1}$ flight control law provided among the best flying qualities rating for each of the stability degradation cases, that is,

6 of 15

American Institute of Aeronautics and Astronautics 
nominal - CHR3, neutrally stable - CHR5, unstable - CHR7. These ratings were provided without a benefit of a non-adaptive baseline to provide nominal stability and performance.

As a companion to the handling qualities ratings, pertinent aircraft dynamics with $\mathrm{L}_{1}$ active are presented for each stability case in Figs. 5 - 7. Recall that the maneuvers were flown in light turbulence and the aircraft angular rates are 4.26 times faster than full scale aircraft dynamics. The offset landing task is designed deliberately so that the pilot is very aggressive on the lateral stick with some corrective action in executing the S-turns that is evident even with the nominal aircraft dynamics, Fig. 5a, and CHR3 rating. As aircraft dynamics are destabilized, the pilot continues to be aggressive with the lateral stick though his corrective actions in trying to compensate for roll overshoot due to reduction in roll damping become more pronounced, Figs. 6a and 7a. The considerable compensation evident from the lateral stick motion is reflected in CHR5 and CHR7 respectively. The longitudinal dynamics, even in the highly unstable case, remain well behaved and require minimal longitudinal stick compensation effort. Similar observation can be made regarding the directional dynamics represented by $\beta$, Figs. 5c - 7c, and yaw rate r, Figs. 5d - 7d. The dominant dynamics in these tasks are lateral axis, in particular roll rate, Figs. $5 \mathrm{~d}-7 \mathrm{~d}$. This behavior is consistent with the fact that destabilizing the aircraft through changes in $C_{l p}$, which is a roll damping, is degrading dynamic stability to neutral and highly unstable. The controller surface commands are reasonable in magnitude and are consistent in frequency with the aircraft dynamics, Figs. 5b - 7b. One potential modification to the control law that suggests itself based on the magnitude of the surface commands would be to allow the rudder to play a larger role in countering the roll rate. Since the rudder is a large and very powerful surface, the rudder response was intentionally kept small in the initial designs at the request of the AirSTAR PI.

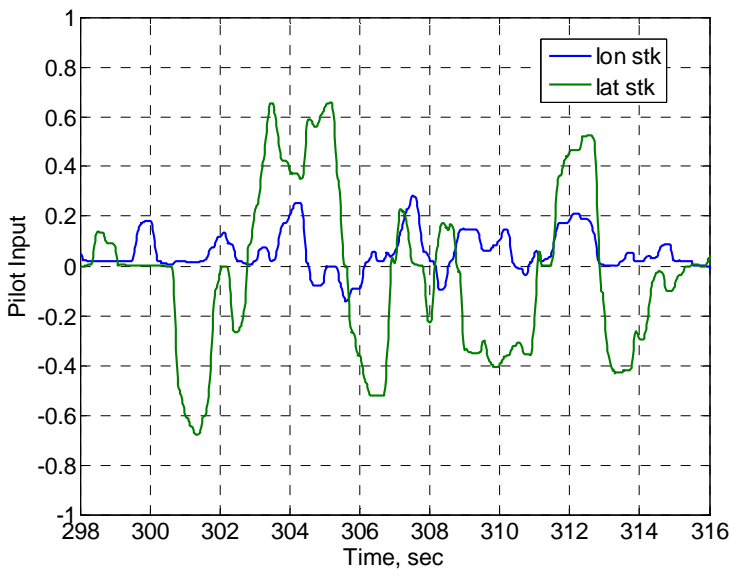

(a) Pilot stick commands

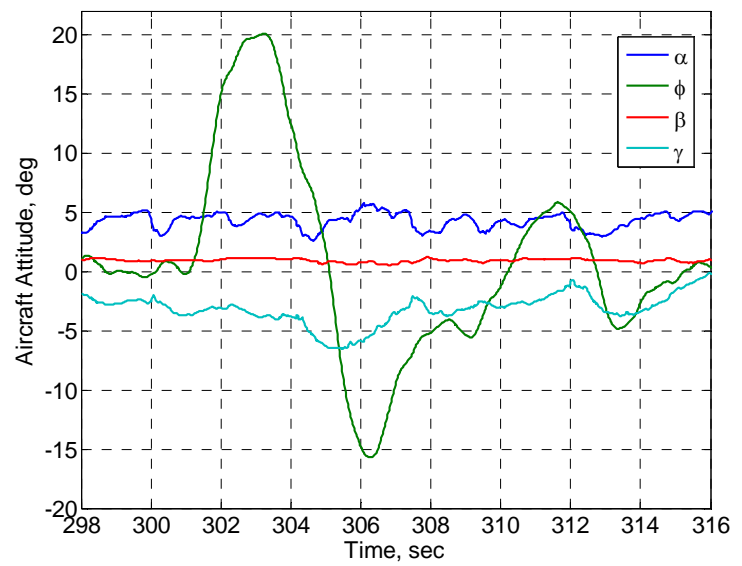

(c) Attitude and flight path response

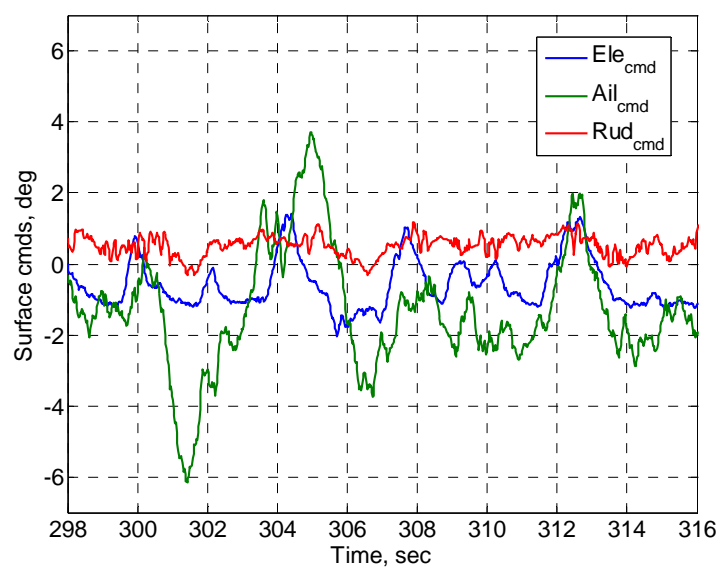

(b) $\mathrm{L}_{1}$ FCL commands

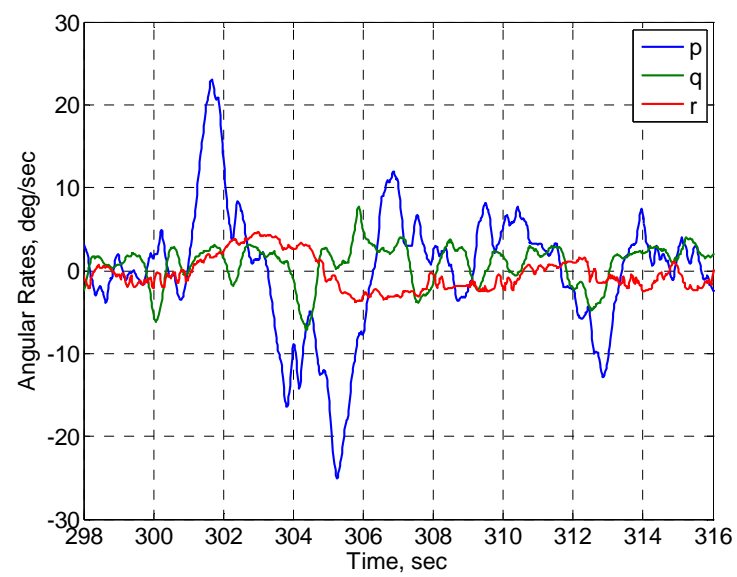

(d) Angular rates response

Figure 5. Nominal aircraft response during offset landing task.

7 of 15

American Institute of Aeronautics and Astronautics 


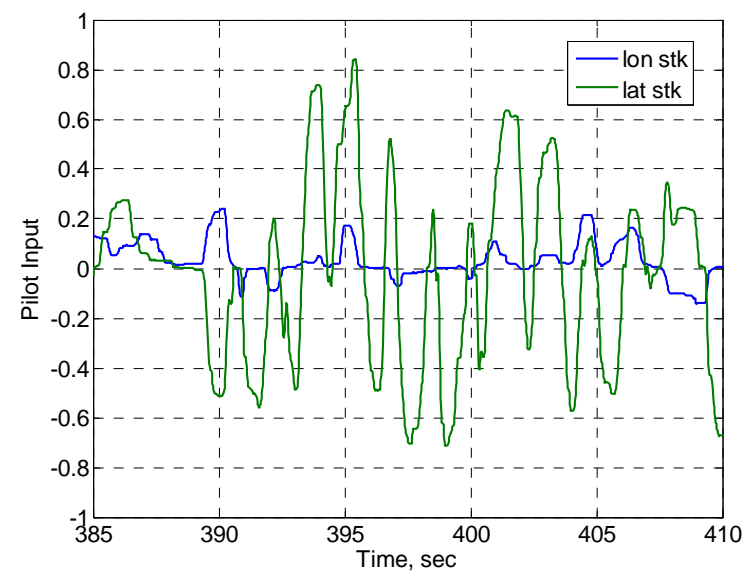

(a) Pilot stick commands

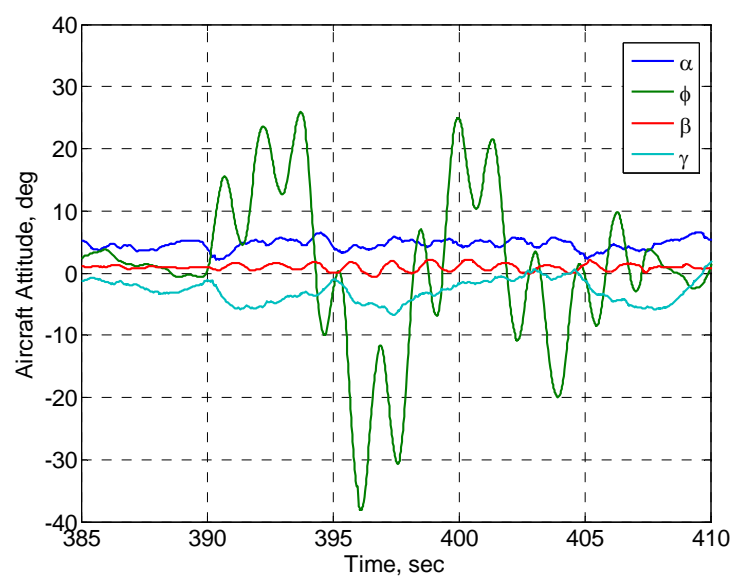

(c) Attitude and flight path response

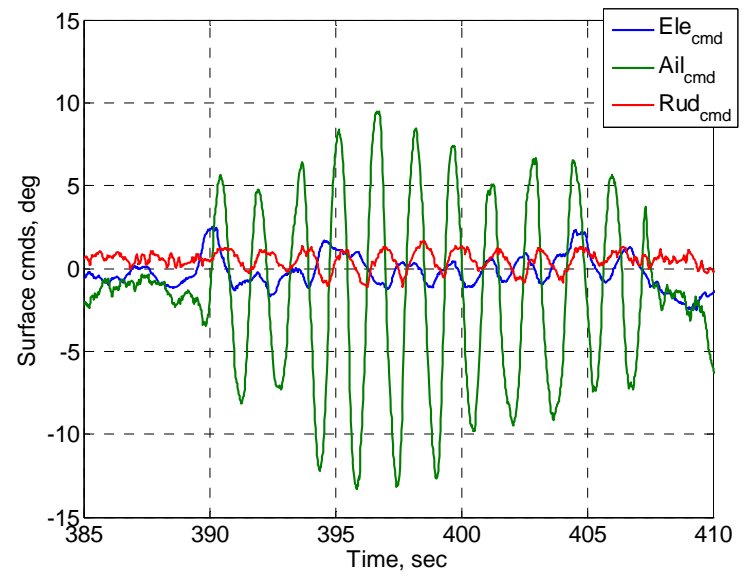

(b) L1 FCL commands

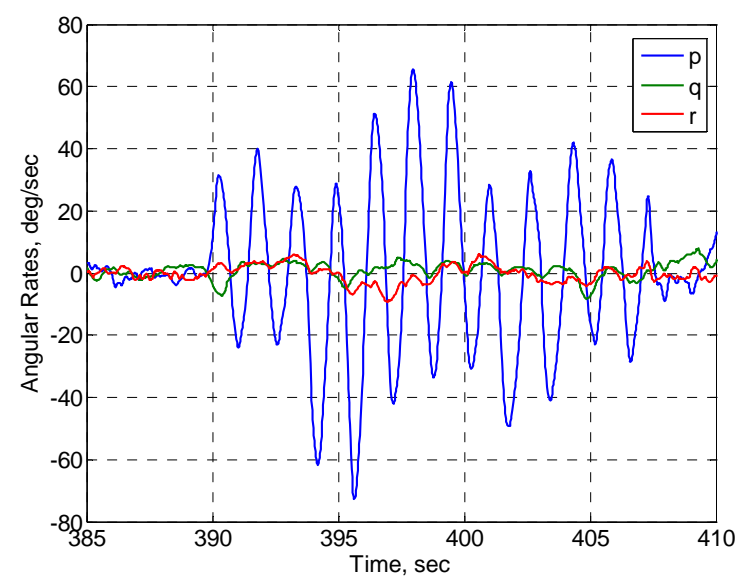

(d) Angular rates response

Figure 6. Neutrally stable aircraft response during offset landing task.

Since bank angle and flight path angle were specified performance quantities, they are plotted cumulatively for offset landings under all 3 stability cases in Fig. 8 a-b. The plots show the quantity in question as the altitude above a simulated runway decreases. The desired and adequate performance boundaries are also plotted in the figures. As mentioned earlier based on the comments, the pilot paid some attention to the bank angle requirements and very little attention to the flight path requirements. There were too many performance items to pay attention to in addition to basic flying that was very challenging, per design, even under nominal conditions. The data plotted in Fig. 8 provide objective evidence to support pilot's comments. As shown in Fig. 8a, the bank angle for the nominal dynamics never leaves the adequate envelope and remains inside the desired envelope in the last $50 \mathrm{ft}$, with apparent landing at 0 deg bank. The bank angle response deteriorates as the aircraft stability deteriorates, but it is evident that an effort is made to minimize bank at landing. In both cases of stability degradation, the bank angle is within desired envelope roughly the last $5-7 \mathrm{ft}$ and certainly within adequate for the neutrally stable aircraft within the last $18 \mathrm{ft}$. The response for flight path angle is much less precise even for the nominal stability case, Fig. 8b, which supports the comment that the pilot was paying little attention to its values.

\section{8 of 15}

American Institute of Aeronautics and Astronautics 


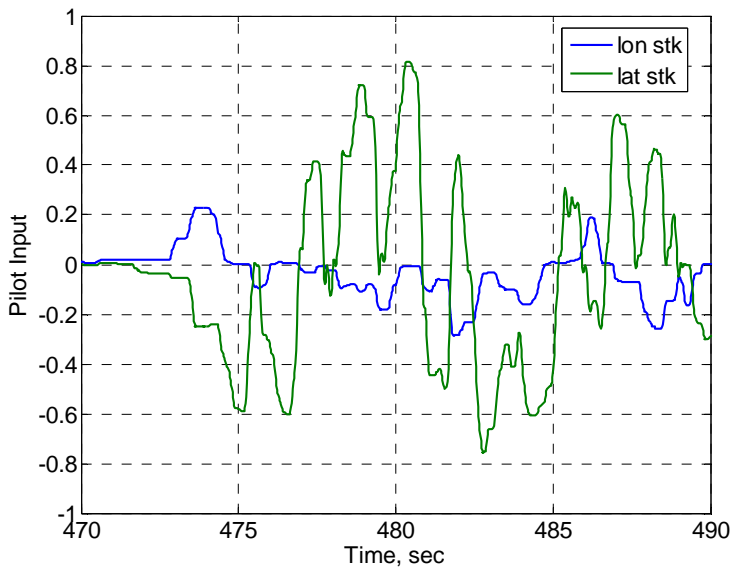

(a) Pilot stick commands

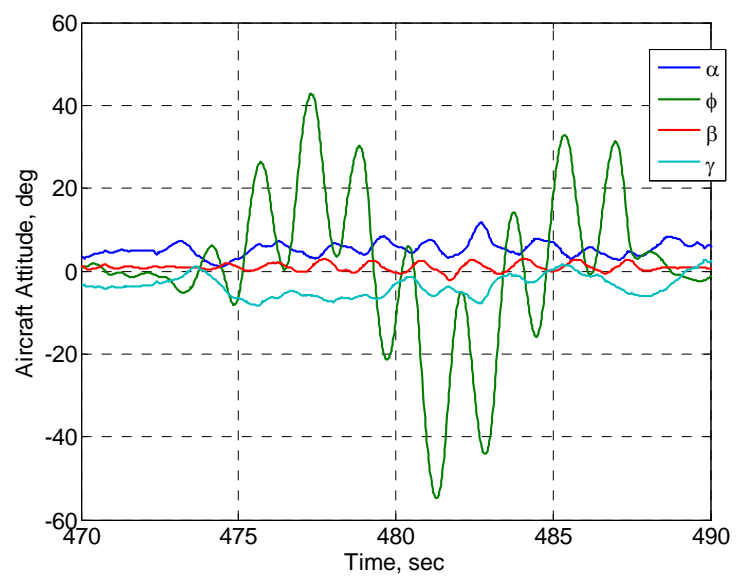

(c) Attitude and flight path response

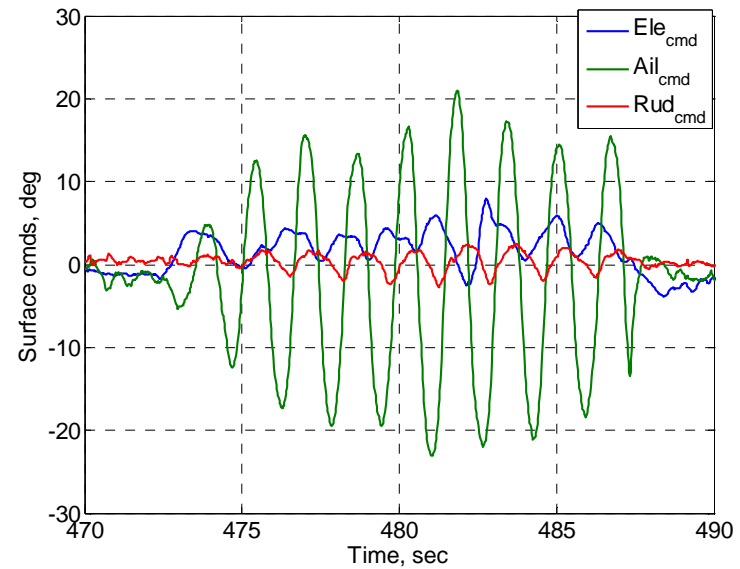

(b) L1 FCL commands

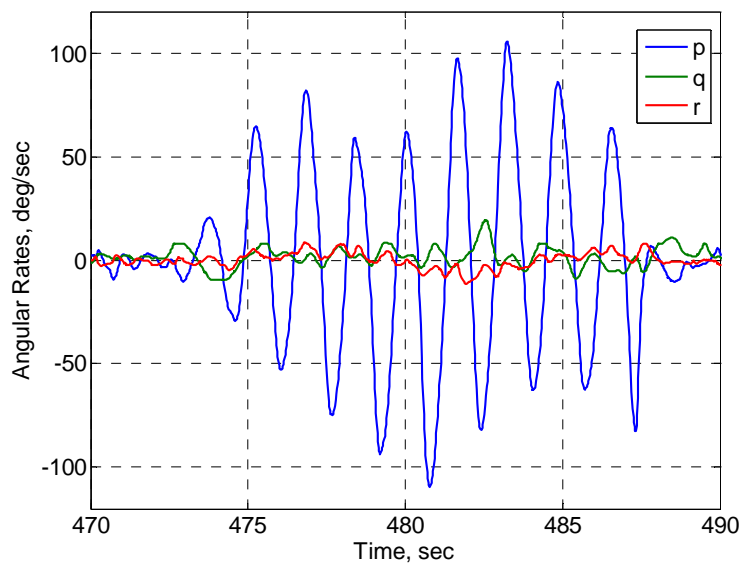

(d) Angular rates response

Figure 7. Unstable stable aircraft response during offset landing task.

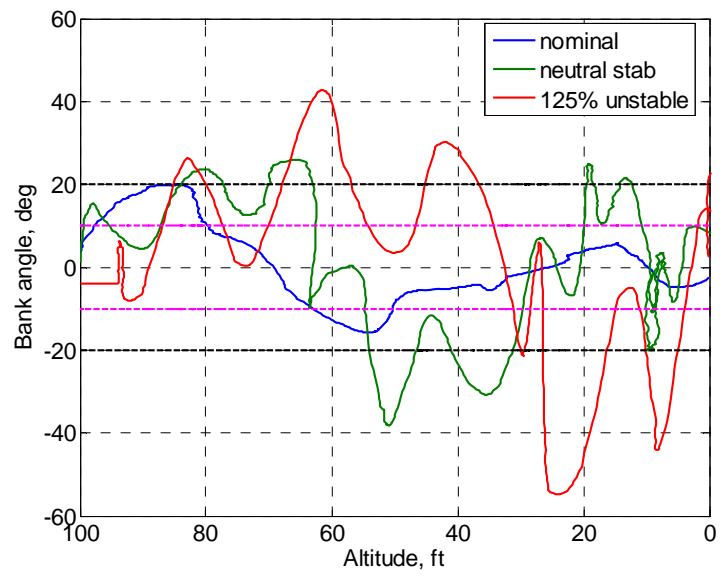

(a) Bank angle response

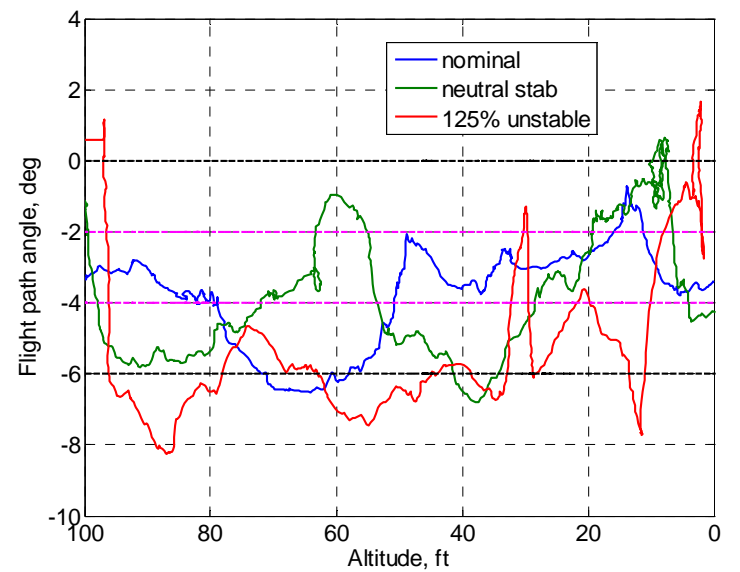

(b) Flight path angle response

Figure 8. Aircraft response during offset landing task for nominal and stability degraded dynamics. [black dashed lines - adequate performance; magenta dashed lines- desired performance] 


\section{B. Objective 2 - Support of large flight envelope modeling tasks}

From the perspective of the Aviation Safety Program, interest in stall and post-stall flight is twofold. First, there is an interest in exploiting the AirSTAR facility as a flying wind tunnel to model unsteady nonlinear aerodynamics encountered in near and post-stall flight regimes. Second, high angle of attack flight provides a challenging scenario for adaptive controllers in which the dynamics of the aircraft experience significant changes and are characterized by uncertain nonlinear phenomena. The primary challenge associated with post-stall high angle of attack is rapidly changing roll damping characteristics and an abrupt wing drop due to asymmetric wing stall. Roll asymmetry with strong roll-off tendency is expected to occur at about 13 deg angle of attack. Also, roll damping characteristics are expected to rapidly change from stable to slightly unstable in the $10 \mathrm{deg}$ to $12 \mathrm{deg}$ angle of attack range. At angles of attack above stall, roll damping was expected to improve and aerodynamic asymmetry was expected to reduce. The defining stall characteristic is expected to be an unstable pitch break occurring at 13 deg angle of attack; moreover, at post-stall 15 deg angle of attack, static and dynamic longitudinal stability is expected to be low.

By the September 2010 deployment, an $\mathrm{L}_{1}$ adaptive control law has established itself as a reliable and predictable tool to be used in support of other research in order to reduce research pilot's workload and provide tighter acquisition of target flight conditions. Part of the September 2010 deployment and all of the May 2011 deployment dealt with large flight envelope modeling tasks. The modeling maneuvers supported by the $\mathrm{L}_{1}$ adaptive control law are outlined in Table 1.

\begin{tabular}{|c|c|}
\hline Task & \multicolumn{1}{|c|}{ Straight leg } \\
\hline Unsteady Aerodynamics Modeling & $\begin{array}{l}\text { Post-Stall High } \alpha \text { Tracking: Attain stable flight at } \alpha=18, \\
\text { inject wavetrain }- \text { Step doublet, Schroeder sweep, variable } \\
\text { frequency Sinusoid } \\
\text { Roll forced oscillations at } \alpha=\mathbf{1 2} \text { : Precise tracking of } \alpha=12, \\
\text { while allowing for free } \beta \text { response to roll wavetrain - Step } \\
\text { doublet, Schroeder sweep, variable frequency Sinusoid }\end{array}$ \\
\hline $\begin{array}{c}\text { RT System Identification: } \\
\text { approach to stall } \\
\text { departure }\end{array}$ & $\begin{array}{l}\text { Wavetrain applied to individual control surfaces } \\
\text { Superimposed on controller commands } \\
\rightarrow \alpha \text { sweep from low } \alpha \text {, through stall to departure ( } \alpha=28)\end{array}$ \\
\hline $\begin{array}{l}\text { Applied } \mathrm{L}_{1} \text { adaptive control to lengthen time on condition with stabilization that allowed slow transition } \\
\text { through stall boundary and improved stall/departure recovery. }\end{array}$
\end{tabular}

Table 1. Modeling maneuvers supported by $L_{1}$ adaptive flight control law

Unsteady nonlinear aerodynamic modeling commenced with longitudinal axis during the September 2010 deployment and continued with lateral axis in May 2011. The objective is to correlating results from CFD, wind tunnel, and flight test experiments and, hence, to validate the nonlinear unsteady aerodynamic models. An $\mathrm{L}_{1}$ adaptive controller enabled unsteady aerodynamic modeling at near and post-stall AOA by providing precision tracking of $\alpha$ inputs used to produce the wind-tunnel model as well as providing precise tracking and stability during

10 of 15

American Institute of Aeronautics and Astronautics 
roll-axis excitation waveforms at $\alpha=12 \mathrm{deg}$. The purpose of these maneuvers is to validate unsteady aerodynamic behavior which was identified in wind-tunnel tests using a forced-oscillation test technique.

Moreover, maneuvers to collect data and demonstrate real-time stability and control parameter identification in numerous off-nominal flight conditions, including stall, post-stall, departure and recovery were conducted. An $\mathrm{L}_{1}$ adaptive control law was used to lengthen time on condition with stabilization that allowed slow transition through stall boundary and improved stall/departure recovery. Furthermore, the FCL provided a more stable aircraft at the departure boundary where there is only partial controllability, thus enabling a safer recovery with less workload.

\section{Task 1 - L ${ }_{1}$ Flight Control Law in Support of Unsteady Aerodynamic Modeling Work}

One of the several research objectives for the AirSTAR facility is to identify high angle of attack dynamics and verify these against obtained wind tunnel and CFD data. In order to do so, the GTM aircraft flight must be able to safely fly at the very edges of the attainable flight envelope. The aerodynamics in the near-stall and post-stall region are nonlinear and increasingly asymmetric with increased $\alpha$.

The control law task to support post-stall high $\alpha$ tracking is to attain stable flight at $\alpha=18 \mathrm{deg}$, and once the desired angle of attack was reached, follow a predetermined input wave train while the pilot stays out of the loop, especially in the longitudinal axis. The aircraft response to the prescribed inputs - step command (18 deg to 15 deg, 15 deg to 20 deg, 20 deg to $15 \mathrm{deg}$ ) and Schroeder sweep - is shown in Fig. 9.

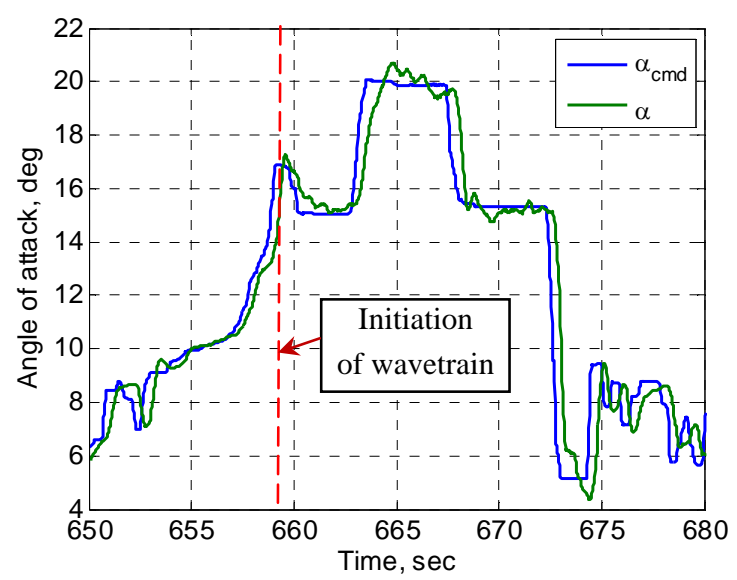

(a) Step input

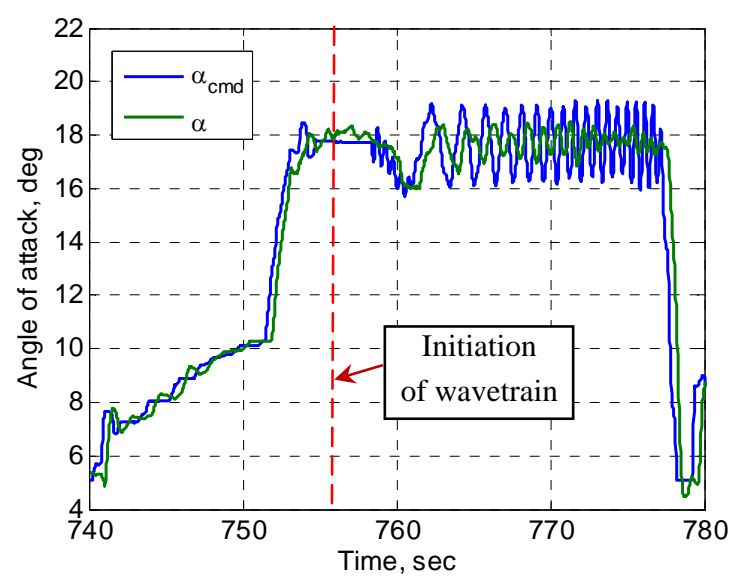

(b) Schroeder sweep

Figure 9. Post-stall angle of attack command following.

Unsteady nonlinear aerodynamic modeling work continued during the May 2011 deployment with the forced roll oscillations exciting the lateral axis. The $\mathrm{L}_{1}$ adaptive controller task is to provide stability during model identification using step doublet, Schroeder sweep and variable frequency sinusoid in the laterally unstable region, $\alpha$ $=12$ deg. The FCL is to provide precise tracking of $\alpha=12$, while allowing for free $\beta$ response to roll wavetrain. Since free $\beta$ response is desired, the strategy is to use only longitudinal $L_{1}$ adaptive controller. A sample of the controller responses to the prescribed inputs are shown in Fig. 10. Column (a) in Fig. 10 shows vehicle response to step doublet in ailerons occurring roughly between 220 and 230 seconds. Note the precise tracking of $\alpha=12$ provided by an $\alpha$-command $L_{1}$ adaptive controller. The lateral/directional axes, $\mathrm{p}$ and $\beta$ are free to respond open loop to the aileron step input. The same set of responses is shown for high amplitude, high frequency Schroeder sweep of the ailerons shown in column (b) of Fig. 10. Again $\alpha=12$ is precisely tracked while $p$ and $\beta$, are free to respond open loop to the aileron input. At this point, this is a very benign tracking task from the adaptive controller perspective. Precise maneuvers that will provide required information to verify the CFD and wind-tunnel models in flight are being modified based on the results from this deployment. An $\mathrm{L}_{1}$ adaptive controller is expected to play a prominent role in whatever set of maneuvers emerges for next deployment.

11 of 15

American Institute of Aeronautics and Astronautics 

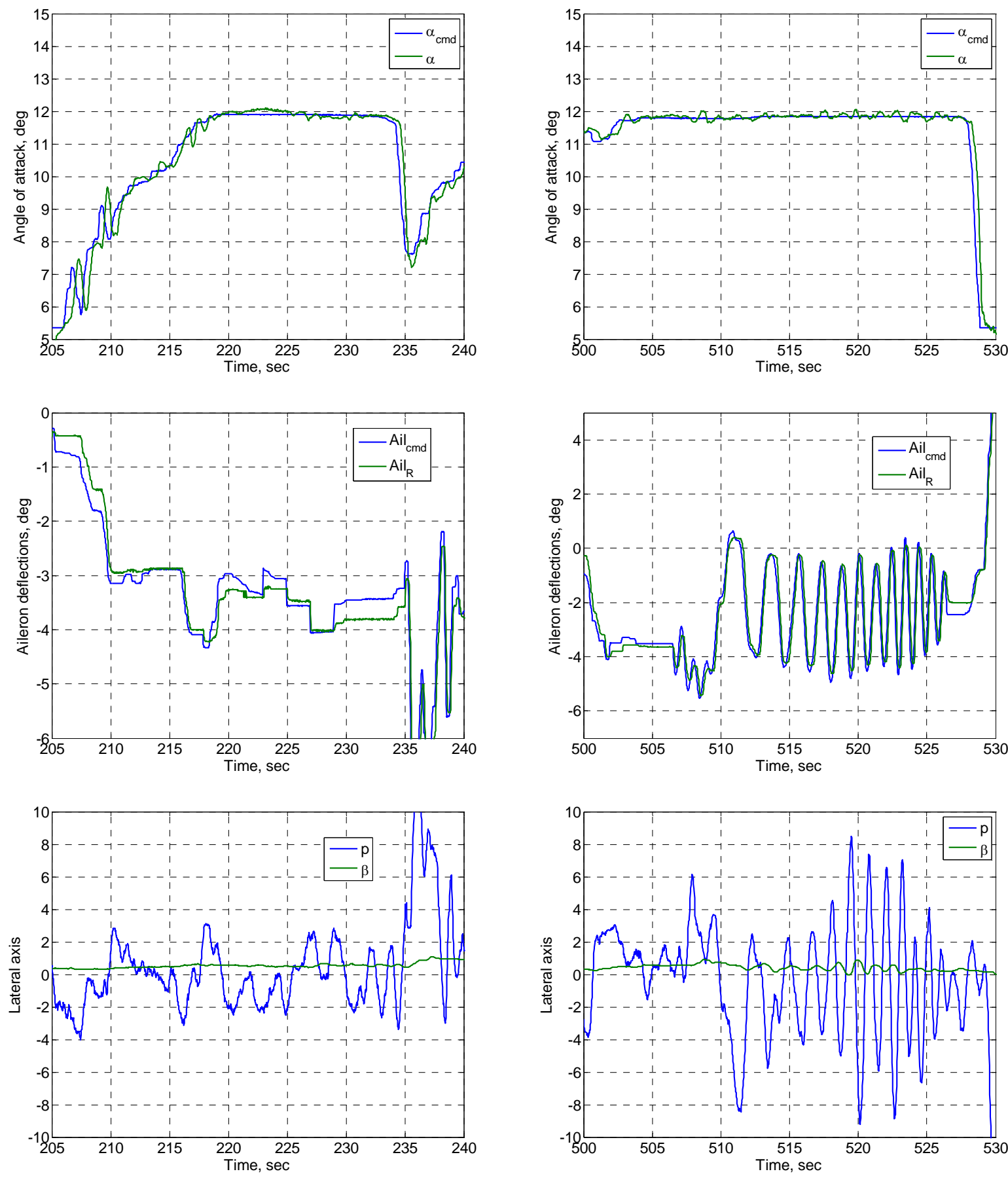

(a) Step input

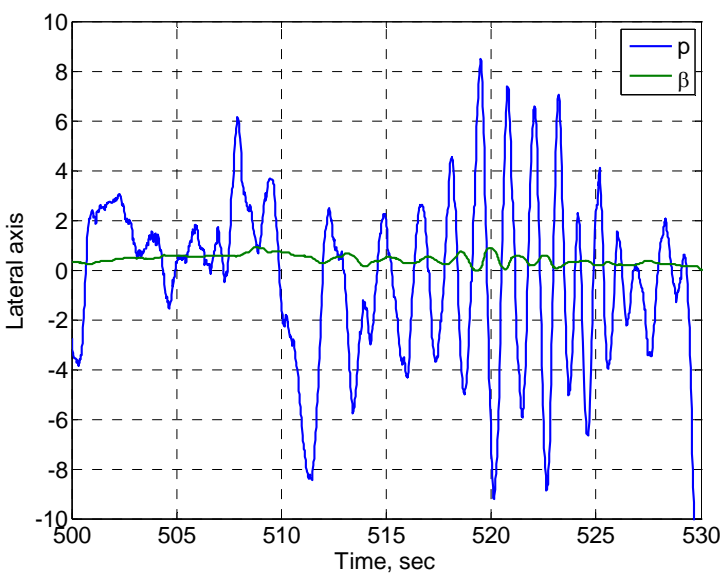

(b) Schroeder sweep

Figure 10. Command following at 12 deg angle of attack with aileron forcing inputs.

Significantly, the control law demonstrates precision tracking capability in the near-stall and post-stall regions. Moreover, the $\mathrm{L}_{1}$ control law provides predictable response to the pilot when the control authority for different axes is divided between a pilot and an automatic command. 


\section{Task 2 - Stall and post-stall flight real-time model identification support}

Finally, during the May 2011 deployment, the $\mathrm{L}_{1}$ adaptive control law continued to enable exploration of departure-prone edges of the flight envelope and support nonlinear unsteady aerodynamic modeling beyond the linear flight regime. The $\mathrm{L}_{1}$ adaptive flight control law was used as a means to maintain departure resistance and to reduce pilot workload during test-point acquisition. The $\mathrm{L}_{1}$ control law allowed the research pilot to operate the aircraft in precarious flight conditions near stall and departure for longer periods of time than Mode1, which provided time for the optimized multi-input wavetrains to excite the aircraft dynamics in all 6 degrees of freedom to collect the data needed for real-time dynamic modeling. Note that Mode1, stick-to-surface, is the only control law in addition to an $\mathrm{L}_{1}$ FCL that is cleared for stall and post-stall flight. The $\mathrm{L}_{1}$ controller operated without introducing high correlations in the states and controls during the maneuvers. Note that the maneuvers were implemented by adding wavetrain perturbation inputs directly to the actuator commands from the control law, just upstream of the load limiting (see Fig. 1).

The range of $\alpha-\beta$ covered during the maneuvers to collect data and demonstrate real-time stability and control parameter identification in numerous off-nominal flight conditions, including stall, post-stall, departure and recovery is illustrated in Fig. 11. Notice the region of $22 \leq \alpha \leq 28$ deg where loss of control is predicted from the nonlinear wind-tunnel based aerodynamic models, which in fact was verified in flight. The region is characterized by limited controllability and abrupt departure. The $\mathrm{L}_{1}$ adaptive control law enabled the aircraft to linger in the departure prone region and made the recovery from very high angle of attack and very large angle of sideslip more predictable with lower workload

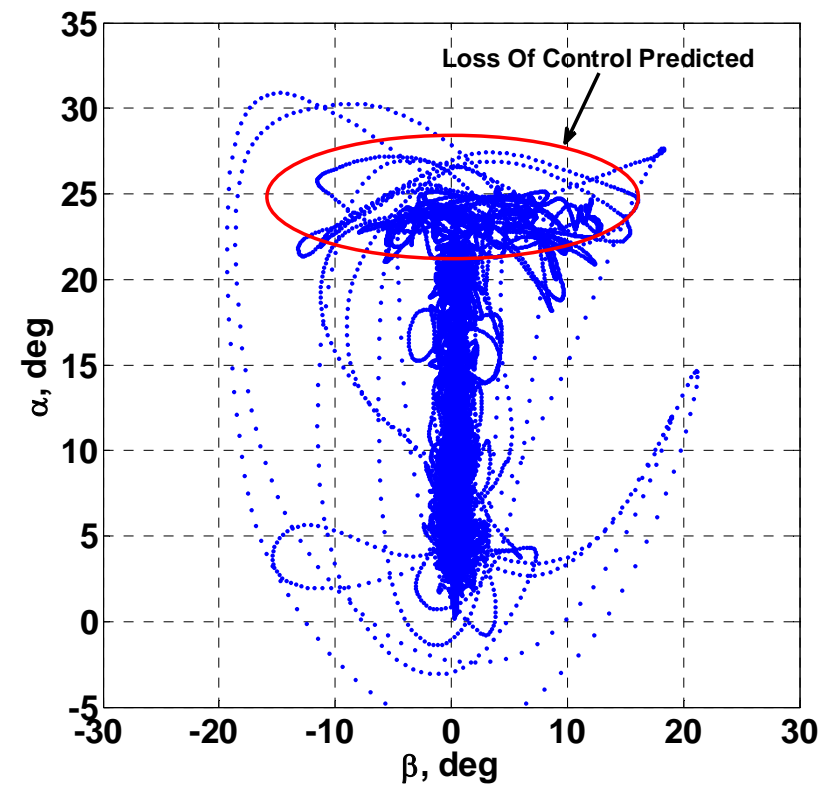

Figure 11. Angle of attack vs. angle sideslip coverage during large envelope modeling.

The $\mathrm{L}_{1}$ adaptive flight control law is used to slowly acquire and capture a post stall angle of attack ( $\left.28 \mathrm{deg}\right)$. This is done both with and without injection of orthogonal multi-sine control surface perturbations. The purpose is to increase the fidelity of aerodynamic parameter estimates at post-stall angle of attack by reducing pilot workload and delaying departure from controlled flight. Based on the nonlinear wind-tunnel model, departure from controlled flight is expected to occur at 24 deg angle of attack. The stall departure mode is expected to be a nose-slice departure, occurring at 24 deg true angle of attack.

Fig. 12 shows a single maneuver used for real-time dynamic modeling of the low angle-of-attack regime, moderate angle-of-attack regime, stall, departure and recovery. An $\mathrm{L}_{1}$ adaptive control law was engaged to lengthen time on condition with stabilization that allowed slow transition through stall boundary and improved stall/departure

13 of 15

American Institute of Aeronautics and Astronautics 
recovery. Fig. 12a shows angle-of-attack buildup from nominal wings level flight to lingering at pre-stall at $\alpha \approx 11 \mathrm{deg}$, followed to progression through stall and ramping up command to $30 \mathrm{deg}$. Departure was predicted by the nonlinear wind-tunnel based models to occur at $\alpha \approx 24 \mathrm{deg}$ and based on the aircraft response is validated in flight. Growing angle of attack oscillations begin roughly at 767 seconds, Fig. 12a, and the beginning of departure characterized by a nose slice is evident from the $\beta$-response at 767 seconds shown in Fig. 12b. Maximum steady state angle of attack has been reached at $\alpha \approx 25 \mathrm{deg}$ based on persistent elevator saturation shown in Fig. 12d, starting at 764 seconds. Angle of attack above 25 deg was reached primarily due to transient effects. Moreover, limitations in control power and vehicle partial controllability become evident from persistent saturation in ailerons starting at $767 \mathrm{sec}$ and near saturation of rudder during the same time frame, Fig. 12d. Full blown departure with large change in angle of attack, Fig. 12a, very large values of bank angle, Fig. 12b, and large roll rates, Fig. 12c, occurs at around 770 sec. The recovery is immediately initiated and successfully completed as can be seen from all rates and attitudes returning to nominal conditions. Note that during this entire maneuver there are control surface perturbations superimposed on the control surface commands from an $L_{1}$ adaptive control law. These control surface excitations can be seen in small oscillatory signals on elevator, aileron, and rudder shown in Fig. 12d.

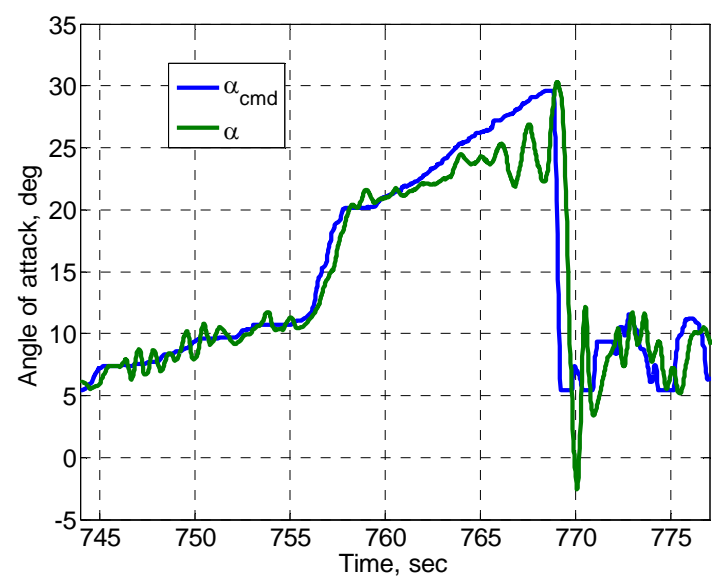

(a) True angle of attack

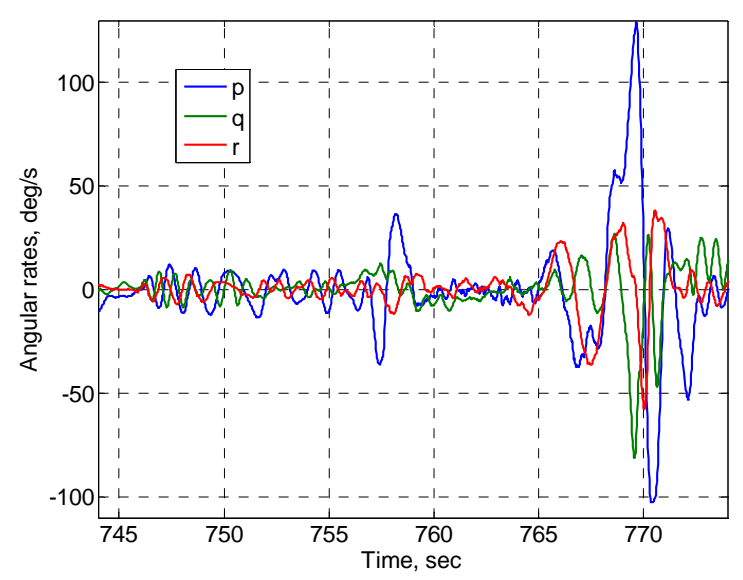

(c) Angular rates

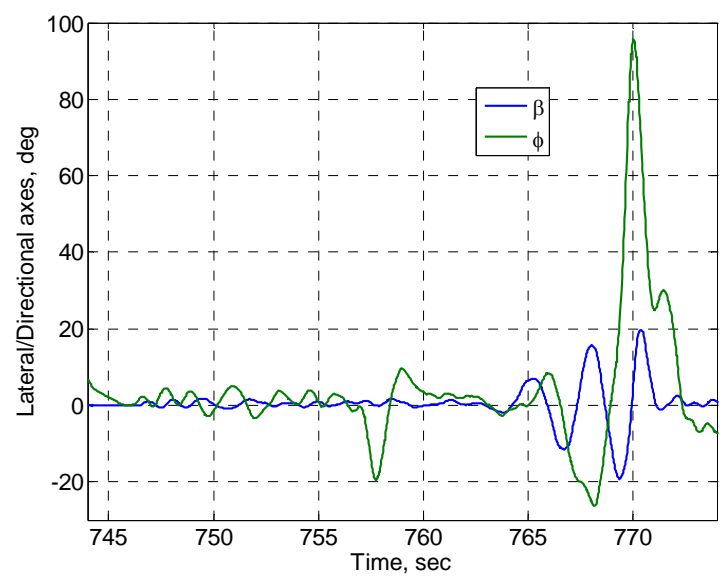

(b) Sideslip and bank angle

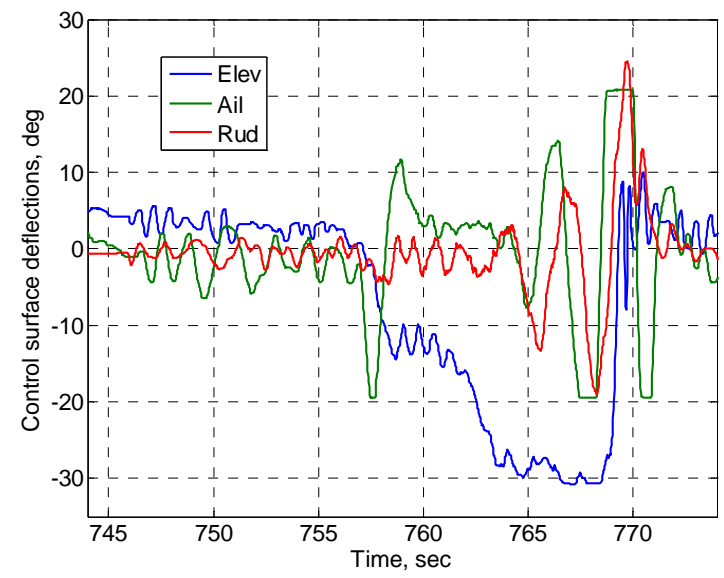

(d) Control surface response

Figure 12. Aircraft response to angle of attack build up to stall, post-stall, departure and recovery while excited by orthogonal multi-sine multi-axis control surface perturbations.

An $L_{1}$ adaptive control law enabled operation at departure-prone edges of the flight envelope and enabled the vehicle to linger near stall and departure for longer periods of time. From the modeling perspective, the deployment

14 of 15

American Institute of Aeronautics and Astronautics 
demonstrated ability to determine real-time stability and control characterization during approach to stall, through departure and recovery. A significant finding is that real-time estimates of open-loop parameters were not noticeably degraded by actions of the controller.

\section{Conclusions / Future Plans}

The series of flight tests on the GTM remotely piloted aircraft conducted with an $\mathrm{L}_{1}$ adaptive control law provided a challenging, real-world environment that stressed the control law to its limits, exposed its behavior in various demanding scenarios, and verified the theoretical predictions of its behavior. The results show that the $\mathrm{L}_{1}$ flight control law provides predictable behavior both in the neighborhood of the design point as well as in other operating points of the flight envelope, such as stall and post-stall regimes. Significantly, the control law demonstrates precision tracking capability at the edge of aircraft controllability even with persistently saturated control surfaces. Moreover, the $\mathrm{L}_{1}$ control law provides predictable response to the pilot when the control authority for different axes is divided between a pilot and an automatic command.

Fast adaptation is critical to ensure safe operation and provide a predictable aircraft behavior for the pilot, even as significant changes in aircraft dynamics happen unexpectedly. In addition, the $\mathrm{L}_{1}$ controller has enabled modeling of unsteady nonlinear aerodynamic phenomena at challenging flight conditions, such as stall and post-stall, and has also enabled real-time dynamic modeling of the departure-prone edges of the flight envelope. In this sense, the $\mathrm{L}_{1}$ flight control law has established itself as a reliable tool to enhance the experimental capabilities of the GTM aircraft, by facilitating precision tracking with reduced pilot workload.

\section{Acknowledgments}

The authors would like to acknowledge the staff of the AirSTAR Flight Test Facility for their support with control law implementation, their insights into flight dynamics and piloted evaluations.

\section{References}

${ }^{1}$ Cunningham K., Foster J. V., Morelli E. A., and Murch A. M., "Practical Application of a Subscale Transport Aircraft for Flight Research in Control Upset and Failure Conditions,” AIAA 2008-6200, AIAA Atmospheric Flight Mechanics Conference, Honolulu, HI, 2008.

2 Murch, A. M., “A Flight Control System Architecture for the NASA AirSTAR Flight Test Infrastructure,” AIAA 20086990, AIAA Guidance, Navigation, and Control Conference and Exhibit, Honolulu, HI, 2008.

${ }^{3}$ Murch, A. M., Cox, D.E, Cunningham K.,” Software Considerations for Subscale Flight Testing of Experimental Control Laws,” The InfoTech@Aerospace 2009, Seattle, WA, April, 2009.

${ }^{4}$ Gregory, I.M., E. Xargay, C. Cao, N. Hovakimyan. Flight test of an $\mathrm{L}_{1}$ adaptive controller on the NASA AirSTAR flight test vehicle. AIAA Guidance, Navigation and Control Conference, Toronto, Canada, August 2010. AIAA-2010-8015.

${ }^{5}$ Xargay, E., Hovakimyan, N. and C. Cao, " $\mathrm{L}_{1}$ Adaptive Controller for Multi-Input Multi-Output Systems in the Presence of Nonlinear Unmatched Uncertainties,” American Control Conference, June 2010, Baltimore, MD, pp. 875-879.

${ }^{6}$ Gregory, I. M., Xargay, E., Cao, C. and Hovakimyan, N. "L $\mathrm{L}_{1}$ adaptive control law in support of large flight envelope modeling task.” In the Proceedings of 1st CEAS Specialists' Conference on Guidance, Navigation \& Control (EuroGNC 2011), 13-15 April 2011, Munich, Germany.

${ }^{7}$ MIL-STD-1797A, Anonymous, “Military Standard, Flying Qualities of Piloted Vehicles,” 1990.

${ }^{8}$ Cunningham, K. AirSTAR flight test cards. Technical Report GTMP-6325 2010.03, V 3.12, August 2010.

${ }^{9}$ Cunningham, K. “AirSTAR Flight Test Plan: 5.5 \% Dynamically Scaled GTM Tail Number T2. Deployment: 2010.03.” GTMP-6326 2010.03, V 1.00, August 18, 2010.

${ }^{10}$ Cunningham, K. AirSTAR flight test cards. Technical Report GTMP-6325 2011.01, V 2.00, April 2010.

${ }^{11}$ Cunningham, K. “AirSTAR Flight Test Plan: 5.5 \% Dynamically Scaled GTM Tail Number T2. Deployment: 2011.01.” GTMP-6326 2011.01, V 2.00, April 24, 2011.

${ }^{12}$ Cooper, G.E. and Harper. R.P., “The Use of Pilot Rating in the Evaluation of Aircraft Handling Qualities,” NASA TN D5153. April 1969.

15 of 15

American Institute of Aeronautics and Astronautics 